\title{
Music Alleviates Learning and Memory Impairments in an Animal Model of Post-Traumatic Stress Disorder
}

\author{
Hasan Saghari ${ }^{1}$, Vahid Sheibani ${ }^{1}$ (D), Khadijeh Esmaeilpour ${ }^{1, *}{ }^{*}$, Naeem ur Rehman ${ }^{2}$ \\ 1 Neuroscience Research Center, Institute of Neuropharmacology, Kerman University of Medical Sciences, Kerman, Iran \\ 2 Department of Pharmacy, COMSATS University Islamabad, Abbottabad Campus, Pakistan \\ * Correspondence: esmaeilpour@kmu.ac.ir;
}

Scopus Author ID 37033758200

Received: 4.06.2020; Revised: 1.07.2020; Accepted: 1.07.2020; Published: 4.07.2020

\begin{abstract}
Post-traumatic stress disorder (PTSD) is the most prevalent disorder that occurs after experiencing life-threatening traumatic or stressful events. The most prevalent problems among PTSD patients are cognitive dysfunctions, including learning and memory impairments. Listening to music has constructive effects on brain functions, neurogenesis, and neuroplasticity, so the aim of the present study was to investigate the effect of music on learning and memory in a rat model of PTSD. Fifty-six adult male Wistar rats (200-250 gr) divided into four main groups (control, music, PTSD, and PTSD+ music) were used. A single prolonged stress (SPS) method was used for inducing PTSD in rats. Anxietylike behaviors and Cognitive functions were evaluated using the Open field, Morris water maze (MWM), and passive avoidance test. Findings demonstrated that SPS induced marked impairment in learning and memory, and anxiolytic behaviors in rats and exposure to music significantly ameliorated these impairments. It seems that music can modulate the destructive effects of SPS on learning and memory at a behavioral level.
\end{abstract}

Keywords: PTSD; Music; Learning and memory; Anxiety-like behavior; rat.

(C) 2020 by the authors. This article is an open-access article distributed under the terms and conditions of the Creative Commons Attribution (CC BY) license (https://creativecommons.org/licenses/by/4.0/).

\section{Introduction}

Post-traumatic stress disorder (PTSD) is one of the main psychiatric disorders with a lifespan prevalence of $5-8 \%$ in the general population [1]. PTSD occurs when a person is exposed to a life-threatening traumatic or stressful events [2].group of symptoms for PTSD includes an intrusion, avoidance, negative alterations in cognition, mood, alterations in arousal and reactivity[3]. Hippocampus, Amygdala, and Medial Prefrontal Cortex are the brain regions involved in the pathophysiology of PTSD[4].one of the most common problems among these patients is cognitive dysfunctions [5]. Amygdala and hippocampus play an important role in learning and memory ability. Memory is an important process enabling humans to survive through learned adaptive behaviors [6]. An animal model of PTSD is similar to various neurodegenerative diseases [5]. Single-prolonged stress (SPS) is frequently used as an animal model for PTSD. This rat model of PTSD was described by liberzon 22 years ago [7]. Studies have shown a reduction in the volume of the hippocampus and amygdala of people suffering from PTSD. [8]. PTSD animal models also resulted in impairments in learning and memory [9-13]. A number of therapies like Eye Movement Desensitization and Reprocessing Therapy [14], Cognitive Processing Therapy [15], Prolong Exposure [16], and Trauma-Focused Cognitive Behavioral therapies [17] are applied for helping and treating patients with PTSD. 
Music, as a non-pharmacological treatment tool has the potential to cure clinical and functional symptoms in individuals struggling with post-traumatic stress [18]. Many researches revealed that therapy with music diminishes stress and anxiety in clinical populations [19-22]. Also, studies have demonstrated that music can reduce emotional distress [23-25], foster social connectedness[26], and improve overall wellbeing [27]. The previous finding showed that listening to music stimulates many regions of the brain from the brainstem to the frontal cortex [28]. The music stimulates the hippocampus, amygdala, nucleus accumbens, and mesolimbic dopaminergic system [29], which also has profound beneficial effects on brain functions, neurogenesis, and neuroplasticity [30,31]. Spatial cognition is improved in developing rats after Music exposure [32]. During the developmental period of the auditory cortex in growing rats, Mozart music could enhance spatial learning and memory [33,34]. Also, it has been shown that classical music significantly improved learning and memory among stress-induced rats [35]. Considering the protective effects of music on learning and memory impairments, it appeared that music has beneficial effects on PTSD-induced cognitive impairments. Therefore, in the present effects of music exposure on anxiety-liked behavior, spatial and passive avoidance learning and memory in an animal model of PTSD were studied.

\section{Materials and Methods}

Fifty-six healthy male Wistar rats (200-250 gr) were used to develop an animal model of PTSD. Animals were kept in accordance with animal care guidelines of Kerman University of Medical Sciences, Kerman, Iran $\left(23 \pm 1{ }^{\circ} \mathrm{C}, 12 \mathrm{~h}\right.$ light/dark cycles and ad-libitum access to food and water). A maximum effort was made to minimize pain and discomfort for the animals. This study was approved by the Kerman Neuroscience Research Center (Ethics code: 97-23). Rats were randomly divided into four main groups (14 rats for each group): control, PTSD, music (mu), PTSD+Music (ptsd.mu), and each group contained two subgroups: seven rats for Open field and Morris water maze tests and seven rats for Shuttle box test. All behavioral experiments were conducted between 9:00 AM and 2:00 PM.

To induce PTSD in animals, the Single Prolong Stress (SPS) procedure was used as one of the most common models proposed by Liberzon et al. in 1997 [7]. According to this method, SPS is conducted in three stages. First, rats were restrained for $2 \mathrm{hr}$ by placing inside a polyethylene restrainer. Second, instantly afterward, 20 minutes forced swim was performed in a cylindrical tank (with $40 \mathrm{~cm}$ diameter, $50 \mathrm{~cm}$ height, and filled two-thirds from the bottom with $24 \mathrm{oC}$ water). Third, following recuperation for $15 \mathrm{~min}$, they were exposed to diethyl ether (Sigma-USA) until the loss of consciousness and then left undisturbed in their home cages. Seven days after PTSD, rats were again brought to the laboratory and were undergone all behavioral tests after one-hour of habituation.

Rats in music groups were exposed to $12 \mathrm{~h}$ daily Mozart's piano sonata K.448 music for seven days, starting from 7:00 to 17:00. Mozart K.448 was usually used in studies that produce a musical effect on the brain of rodents [36-38].

Arena made of Plexiglas $(90 \times 90 \times 45) \mathrm{cm}$ was used for the Open field test. The apparatus floor was divided into 16 squares, so the field was divided into central and peripheral squares. To check spontaneous locomotors activity, anxiety, fear-related behavior, including total distance moved in $\mathrm{cm}$ (TDM), a number of grooming and rearing, time spent in periphery and center, the animal was placed in the center of the arena, and their behavior was recorded for 5 min with Ethovision video-tracking system [39]. 
MWM was performed to evaluate related hippocampal learning and memory. Rat uses spatial clues while swimming to locate a submerged platform. The test chamber was a circular pool $(160 \mathrm{~cm}$ diameter and $60 \mathrm{~cm}$ deep), which was filled with water $(35 \mathrm{~cm}$ depth and $25 \pm$ $0.5^{\circ} \mathrm{C}$ ) and surrounded by visual cues visible to animals. A circular submerged platform (15 $\mathrm{cm}$ wide and $35 \mathrm{~cm}$ height) was placed $1.5 \mathrm{~cm}$ below the water surface at a fixed location in the center of one of the four imaginary quadrants. In the learning phase, three blocks were fulfilled, and each block has four trials. During each trial, animals were inadvertently released into one of the quadrants and permitted to swim for $60 \mathrm{~s}$ to probe concealed platform. The location of the platform did not change during the acquisition trials, and each rat was allowed to swim for $60 \mathrm{~s}$ to find the platform. After the locating platform, each animal was allowed to remain there for 20-30 s and then returned to its cage to wait for 20-30 s before the start of the next trial. The time and distance traveled to find the escape platform was recorded in each trial. A single probe trial was performed $2 \mathrm{~h}$ after the last block to test spatial short term memory retention. In this trial, the platform was removed, and animals were allowed to swim freely for $60 \mathrm{~s}$. The distance and time spent in the target quadrant were collected for each rat to measure spatial memory. Behavioral data for MWM was collected using Ethovision automation software (Noldus Ethoviion ${ }^{\circledR}$ system, version 7, Netherland), rats could be traced on the screen of a computer [39]. All experiments were carried out between 9:00 AM and 2:00 PM.

In Passive avoidance test (PAT) rats learned to avoid an environment in which a prior aversive stimulus has been delivered. The apparatus consisted of two compartments (dark and light $)$ of the same size $(20 \times 20 \times 30 \mathrm{~cm} 3)$ separated by a door that could be lifted manually. This test had two phases: learning and memory. The rats were allowed to habituate in the experimental room for at least 30 min before experiments. Then, each animal was gently placed in a brightly lit compartment of apparatus; after $5 \mathrm{~s}$ the door was opened, and the animal was allowed to enter the dark module. The latency with which animals entered the dark chamber was recorded. Animals that waited for more than $120 \mathrm{~s}$ to enter the dark chamber were excluded from experiments. Finally, one hour after previous exposure to the apparatus, the animal was placed into a light compartment, the door was opened, and, on entering the dark compartment, it was given an electric shock ( $0.5 \mathrm{ma}, 2 \mathrm{~ms}$; via wires embedded in dark chamber floor). This phase was repeated up to five times at a 1-hour interval until the animal learned to avoid dark compartment (remains in the light compartment for at least $300 \mathrm{~s}$ ), and the number of shocks required for learning was recorded. The memory phase of the test was performed 2 hours after the learning phase. The animal was placed in a light chamber (door closed), and, after $5 \mathrm{~s}$, the door was opened, and the time taken by the animal to enter the dark chamber was recorded as Step-Through Latency (STL). The total time spent in the Dark Compartment (TDC) over a duration of 5 minutes after the door opening was also recorded[40]. After each trial, the apparatus was cleaned using $70 \%$ alcohol.

The data were averaged and offered as Mean \pm SEM. The effect of music on spatial learning rates among different groups in MWM was evaluated by repeated measure two-way ANOVA followed by a Tukey's post hoc test. Data obtained in MWM probe trials, open field, and passive avoidance test were analyzed by a one-way ANOVA. All post-hoc comparisons were made using Tukey's post-hoc test. A P value of less than 0.05 was considered statistically significant. All statistical analyses were done using SPSS software (version 22.0). 


\section{Results and Discussion}

\subsection{Effect of PTSD and music on locomotion and anxiety-like behaviors in an open field test.}

As shown in an open field test, time spent in inner zone (Fig. 1-A) and frequency of rearing (Fig. 1-C) and grooming (Fig. 1-D) in PTSD group were significantly altered $(\mathrm{P}<0.01$, $\mathrm{P}<0.001$ and $\mathrm{P}<0.05$ respectively) compared to control group which indicated PTSD could disturb these anxiety-liked behaviors. The number of rearing behavior and time spent in the inner zone was significantly ( $\mathrm{P}<0.01$ and $\mathrm{P}<0.05$ respectively) changed in $\mathrm{PTSD}+$ Music group (ptsd.mu) compared to PTSD group (PTSD), which revealed music could improve these anxiety-liked behaviors. There is no significant difference between all groups in the total distance, which implies that there is no impaired motor function (Fig. 1-B).
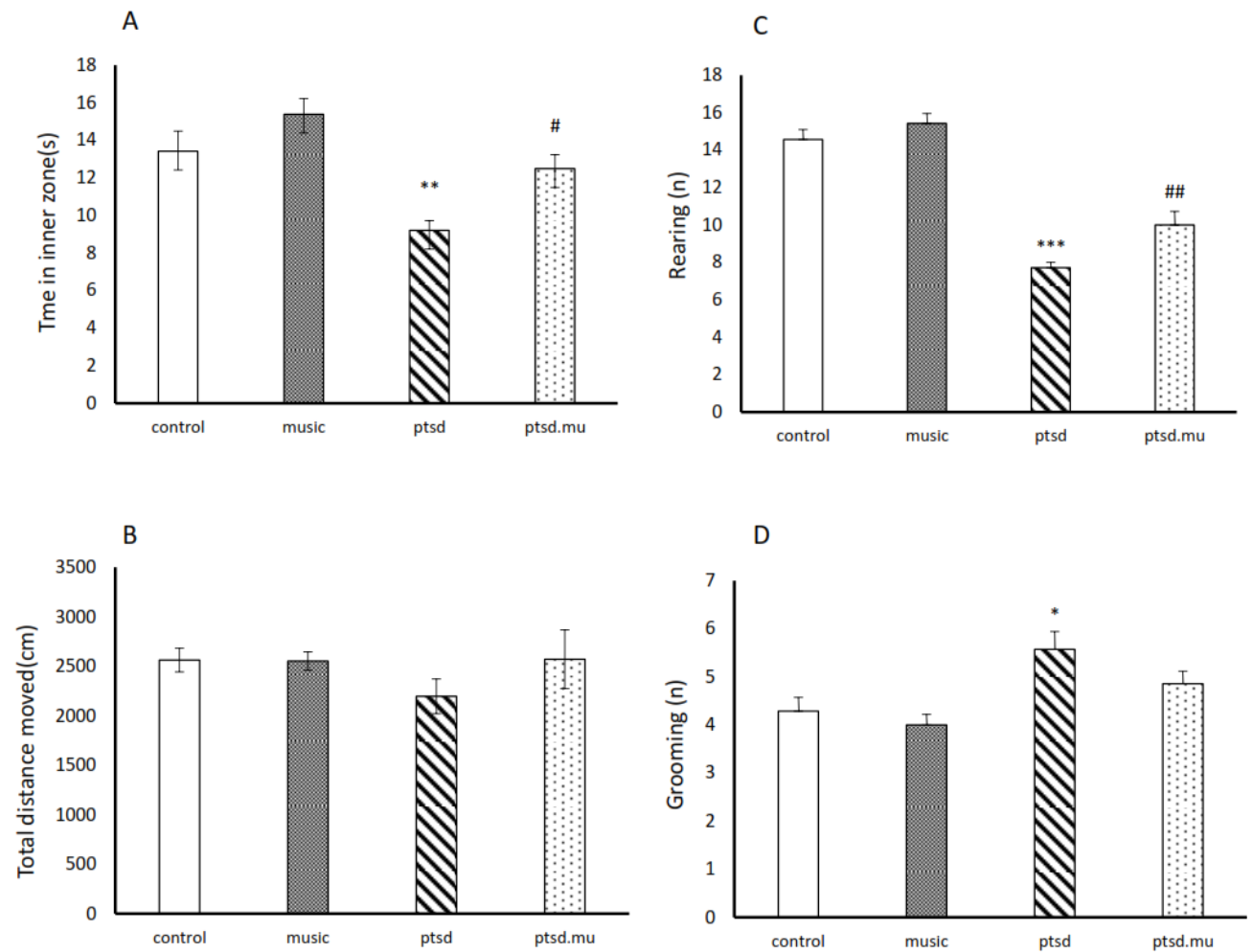

Figure 1. The effect of PTSD and music on locomotion and anxiety-like behaviors using with open field test. * $\mathrm{P}<0.05, * * \mathrm{p}<0.01$ and $* * * \mathrm{p}<0.001$ in comparison to the control groups and $\# \mathrm{p}<0.05$, \#\# $\mathrm{p}<0.01$ in comparison to ptsd group.

\subsection{Effect of PTSD and music on learning and memory in the Morris water maze test (MWM).}

Reducing in the escape latency and swimming path length to explore the hidden platform in MWM during training blocks was acknowledged as spatial learning. Two-way ANOVA revealed that there were statistically significant differences in escape latency $(\mathrm{p}<0.05$ in block 1 and 2 and $\mathrm{p}<0.001$ in block 3 ) and path length ( $<<0.05$ in block $1, \mathrm{p}<0.01$ in block 2 and $p<0.001$ in block 3 ) to explore the hidden platform in PTSD group compared to control group, showing spatial learning impairment in PTSD rats. Also, as shown, scape latency and path length were significantly ( $p<0.001$ and $p<0.01$ respectively) diminished in PTSD.mu group as compared to PTSD group in block 3. It seems music could improve spatial learning in PTSD rats (Fig. 2 A-B). 

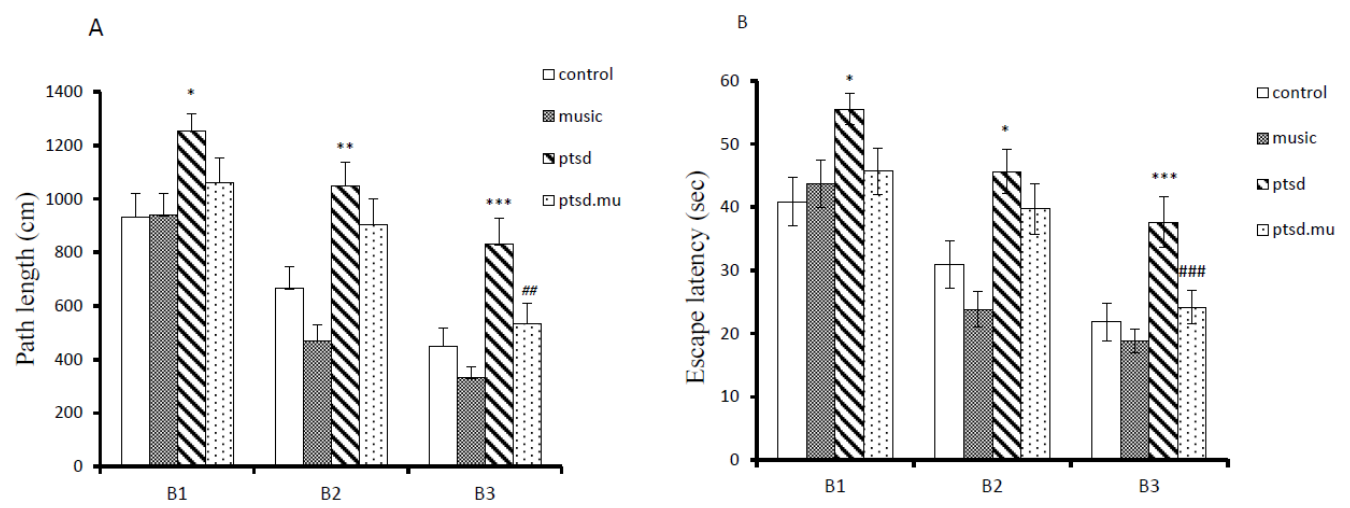

Figure 2. The effect of PTSD and music on spatial learning in MWM task. $* \mathrm{p}<0.05, * * \mathrm{p}<0.01$ and $* * * \mathrm{p}<$ 0.001 in comparison to the control groups and \#\# $\mathrm{p}<0.01$, \#\#\# $\mathrm{p}<0.001$ in comparison to ptsd group.

Two hours after the training phase (acquisition phase), short-term memory retention was tested. The mean percentage (\%) for time and distance in the target quadrant was analyzed data for the retention test. By one-way ANOVA indicated that these parameters were decreased in PTSD group compared to the control group ( $\mathrm{p}<0.05)$. It showed that PTSD could disturb spatial memory. There was no statistically significant difference between PTSD group and PTSD.mu group. Therefore music did not affect spatial memory in PTSD rats (Fig. 3 A-B).
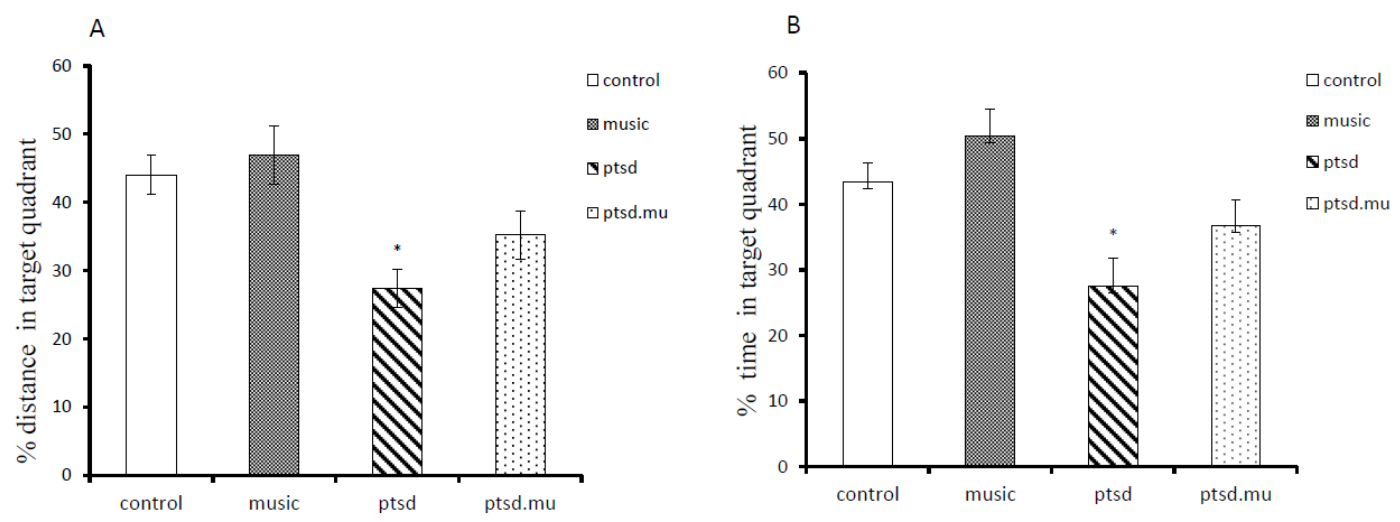

Figure 3. The effect of PTSD and music on spatial memory in MWM task. ${ }^{*} \mathrm{p}<0.05$ in comparison to the control.

\subsection{Effect of PTSD and music on learning and memory in passive avoidance test (Shuttle Box).}

The influence of PTSD and music on passive avoidance learning is shown in Fig. 4-A. One-way ANOVA results indicated that the number of shocks received by animals of PTSD group was significantly higher than those of the control group during the training session $(\mathrm{P}<0.05)$. This indicates learning impairment in PTSD animals. Exposing ptsd.mu group to music decreased the number of shocks in comparison to PTSD group $(\mathrm{P}<0.05)$. It showed that music could improve PTSD-induced learning impairment. The short term memory retrieval was performed $2 \mathrm{~h}$ following a training session and step-through latency (STL). Time spent in a dark compartment (TDC) was analyzed to evaluate short term memory retrieval. The TDC and STL were also altered in PTSD group in comparison with control groups $(\mathrm{P}<0.001)$. This clearly revealed memory impairment in these animals. Our findings indicated that exposing PTSD rats to music in ptsd.mu group ameliorated their memory deficit $(\mathrm{P}<0.05)$ compared to PTSD group (Fig. 4 B-C). 
A
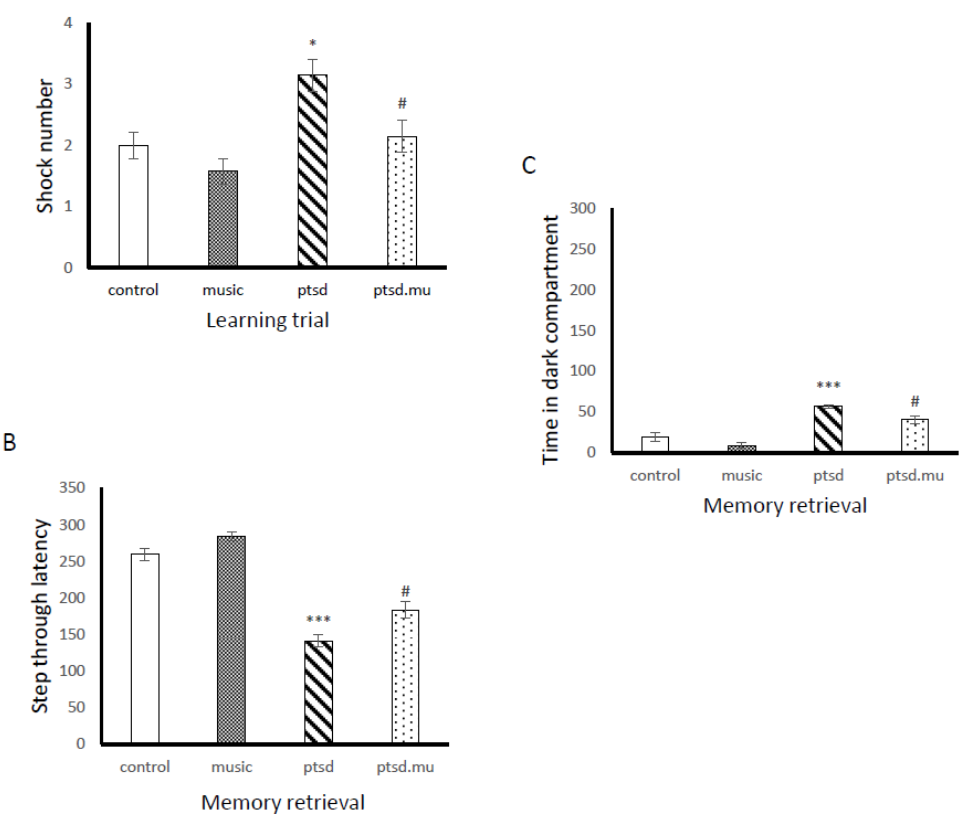

Figure 4. The effect of PTSD and music on passive avoidance learning and memory in the Shuttle box test. * p $<0.05$, and $* * * \mathrm{p}<0.001$ in comparison to the control groups and \# $\mathrm{p}<0.05$ in comparison to PTSD group.

\subsection{Discussion.}

Influence of PTSD induced by SPS on anxiety-like behaviors, spatial, and passive avoidance learning and memory was analyzed, and then the effects of music on impairment in cognitive behaviors induced by PTSD were also studied. Principal findings of this study are that (I) PTSD induced marked impairment of learning and memory and anxiolytic behaviors in rats; (II) exposure to music significantly improved and ameliorated these impairments.

PTSD, as a debilitating condition, significantly declines the quality of life in patients[41]. PTSD-induced animals show severe degenerative alterations and neuronal cell loss in the autonomic nervous and sensory system[42-45]. Excessive stress is known to cause a deteriorative effect on cognition and memory in humans and animal models[46,47].

Our results are consistent with Masoumi-Ardakani et al. (2017) results, which demonstrated that SPS caused anxiolytic behaviors in rats[48]. Also, previous studies have shown that SPS produced spatial memory impairments in Morris water maze [49-51]. Elizalde et al. (2008) revealed that chronic mild stress induces recognition memory deficits in mice [52]. Another study indicated that social isolated stress impaired passive avoidance learning and memory[53], in this study it is revealed that SPS procedure could also induce these types of impairments

Over the past decades, numerous studies have focused on identifying the pathophysiology of PTSD. It has been suggested that structural brain abnormalities associated with PTSD mainly involve the amygdala, hippocampus, and medial prefrontal cortex[54]. The hippocampus, in particular, is thought to be involved because of its critical role in learning and memory, as well as its regulation of the hypothalamic-pituitary-adrenocortical axis[55]. Since dendrite atrophy and neuronal cell death occurs in PTSD and chronic stress exposure, memory impairment, and behavioral malfunctions are seen [56].

To our knowledge, this research is first showing the effect of music in PTSD animal model. The results showed that music alleviated anxiety-like behaviors, spatial learning, and passive avoidance learning and memory impairments induced by PTSD. 
Several drugs, like selective serotonin reuptake inhibitors (SSRI) and serotoninnorepinephrine reuptake inhibitors (SNRI) have been proposed to prevent and treat symptoms of PTSD. [57]. Although they have positive effects on PTSD symptoms, their use is restricted because of various side effects, which clarifies the need for more research on therapeutic modalities [58].

Music can help to reduce anxiety in animals [59] and humans [60]. Research has shown that physiologic markers of stress in humans were improved after a music therapy intervention [60]. Also, there have been putative effects of music on learning and memory. Evidence has increasingly proved that spatial learning and working memory acquisition and retention in mice, rats, and humans, are ameliorated by exposure to music[61]. Merely by listening to music, more regions of the brain are stimulated from the brainstem to the frontal cortex compared to any other activity[28]. Yao et al. found that Mozart's K.448 can improve the electrical activities of neurons of hippocampal CA1, which is an important part of emotional, behavioral, learning, memory, and other high-level neural activities[33]. Another report has indicated the brain development and neuroplasticity by mechanisms that involve facilitated hippocampal neurogenesis, neurotrophin synthesis, and glutamatergic signaling was modulated by exposure of music in rodents[62].

Previous studies reported that Music exposure results in increased rodents' spatial learning and memory [63]. One study examining retrograde versions of Mozart K.448 showed adverse effects that on spatial memory. This effect was also present when rodents heard music for the first time[32]. Our results indicated that music could not significantly improve spatial memory in PTSD rats. This discrepancy may have arisen from the difference in duration of music exposure.

\section{Conclusions}

In summary, our findings indicated that SPS, as a model of PTSD induction in rats, caused anxiolytic behaviors and learning and memory impairments in rats. Furthermore, exposure to music significantly improved and ameliorated these impairments. This is the first study indicating the efficacy of music in an animal model of PTSD. In our study, the mechanism by which music alleviated the impairments induced by SPS in rats is not studied. Further studies examining the neural mechanisms underlying the effect of music in the treatment of PTSD are needed for a better understanding of the pathophysiology of PTSD and the development of novel therapeutic strategies for PTSD.

\section{Funding}

This research was funded by the Kerman Neuroscience Research Center (Grant No: KNRC/EC/97-23).

\section{Acknowledgments}

This study was supported by the Kerman Neuroscience Research Center, Kerman University of Medical Sciences, Kerman, Iran.

\section{Conflicts of Interest}

The authors declare no conflict of interest. 


\section{References}

1. Baker, D.G.; Nievergelt, C.M.; O'Connor, D.T. Biomarkers of PTSD: neuropeptides and immune signaling. Neuropharmacology 2012, 62, 663-673, https://doi.org/10.1016/j.neuropharm.2011.02.027.

2. Eskandarian, S.; Vafaei, A.A.; Vaezi, G.H.; Taherian, F.; Kashefi, A.; Rashidy-Pour, A. Effects of systemic administration of oxytocin on contextual fear extinction in a rat model of post-traumatic stress disorder. Basic and clinical neuroscience 2013, 4 .

3. APA, A.P.A. Diagnostic and statistical manual of mental disorders. DSM-IV 1994.

4. Saffari, S.; Abrari, K.; Rezaei, A.; Rashidy-Pour, A.; Goudarzi, I.; Salmani, M.E. Correlation of fear memory in a PTSD animal model and hippocampal BDNF in response to $\beta$-estradiol treatment. Am Pol Sci Assoc 2015, 85, 61-65, https://doi.org/10.30773/pi.2017.06.17.1.

5. Kim, B.K.; Seo, J.H. Treadmill exercise alleviates post-traumatic stress disorder-induced impairment of spatial learning memory in rats. Journal of exercise rehabilitation 2013, 9, 413-419, https://doi.org/10.12965/jer.130058.

6. Souza, R.R.; Noble, L.J.; McIntyre, C.K. Using the single prolonged stress model to examine the pathophysiology of PTSD. Frontiers in pharmacology 2017, 8, https://doi.org/10.3389/fphar.2017.00615.

7. Liberzon, I.; Krstov, M.; Young, E.A. Stress-restress: effects on ACTH and fast feedback. Psychoneuroendocrinology 1997, 22, 443-453, https://doi.org/10.1016/S0306-4530(97)00044-9.

8. Koelsch, S. Brain correlates of music-evoked emotions. Nature Reviews Neuroscience 2014, 15, 170-180, https://doi.org/10.1038/nrn3666.

9. Nazeri, M.; Shabani, M.; Ravandi, S.G.; Aghaei, I.; Nozari, M.; Mazhari, S. Psychological or physical prenatal stress differentially affects cognition behaviors. Physiology \& behavior 2015, 142, 155-160, https://doi.org/10.1016/j.physbeh.2015.02.016.

10. Goodman, J.; McIntyre, C.K. Impaired spatial memory and enhanced habit memory in a rat model of posttraumatic stress disorder. Frontiers in pharmacology 2017, 8, https://doi.org/10.3389/fphar.2017.00663.

11. Lambert, H.K.; McLaughlin, K.A. Impaired hippocampus-dependent associative learning as a mechanism underlying PTSD: A meta-analysis. Neuroscience \& Biobehavioral Reviews 2019, https://doi.org/10.1016/j.neubiorev.2019.09.024.

12. Salehabadi, S.; Abrari, K.; Salmani, M.E.; Nasiri, M.; Lashkarbolouki, T. Investigating the role of the amygdala orexin receptor 1 in memory acquisition and extinction in a rat model of PTSD. Behavioural Brain Research 2020, 384, https://doi.org/10.1016/j.bbr.2019.112455.

13. Sullivan, D.R.; Marx, B.; Chen, M.S.; Depue, B.E.; Hayes, S.M.; Hayes, J.P. Behavioral and neural correlates of memory suppression in PTSD. Journal of psychiatric research 2019, 112, 30-37, https://doi.org/10.1016/j.jpsychires.2019.02.015.

14. Pitman, R.K.; Orr, S.P.; Altman, B.; Longpre, R.E.; Poiré, R.E.; Macklin, M.L. Emotional processing during eye movement desensitization and reprocessing therapy of Vietnam veterans with chronic post-traumatic stress disorder. Comprehensive psychiatry 1996, 37, 419-429, https://doi.org/10.1016/S0010440X(96)90025-5.

15. Foa, E.B.; Dancu, C.V.; Hembree, E.A.; Jaycox, L.H.; Meadows, E.A.; Street, G.P. A comparison of exposure therapy, stress inoculation training, and their combination for reducing post-traumatic stress disorder in female assault victims. Journal of consulting and clinical psychology 1999, 67, https://doi.org/10.1037//0022-006x.67.2.194.

16. Resick, P.A.; Monson, C.M.; Chard, K.M. Cognitive processing therapy: Veteran/military version. Clinical Psychology 2006, 74, 898-907.

17. Cohen, J.A.; Mannarino, A.P.; Kliethermes, M.; Murray, L.A. Trauma-focused CBT for youth with complex trauma. Child abuse \& neglect 2012, 36, 528-541, https://doi.org/10.1016/j.chiabu.2012.03.007.

18. Landis-Shack, N.; Heinz, A.J.; Bonn-Miller, M.O. Music therapy for post-traumatic stress in adults: A theoretical review. Psychomusicology: Music, Mind, and Brain 2017, 27, https://doi.org/10.1037/pmu0000192.

19. Gold, C.; Voracek, M.; Wigram, T. Effects of music therapy for children and adolescents with psychopathology: a meta-analysis. Journal of Child Psychology and Psychiatry 2004, 45, 1054-1063.

20. Guetin, S.; Portet, F.; Picot, M.; Pommié, C.; Messaoudi, M.; Djabelkir, L.; Olsen, A.; Cano, M.; Lecourt, E.; Touchon, J. Effect of music therapy on anxiety and depression in patients with Alzheimer's type dementia: randomised, controlled study. Dementia and geriatric cognitive disorders 2009, 28, 36-46, https://doi.org/10.1159/000229024.

21. Erkkilä, J.; Punkanen, M.; Fachner, J.; Ala-Ruona, E.; Pöntiö, I.; Tervaniemi, M.; Vanhala, M.; Gold, C. Individual music therapy for depression: randomised controlled trial. The British journal of psychiatry 2011, 199, 132-139, https://doi.org/10.1192/bjp.bp.110.085431.

22. Lee, Y.J.; Kim, M.A.; Park, H.J. Effects of a laughter programme with entrainment music on stress, depression, and health-related quality of life among gynaecological cancer patients. Complementary Therapies in Clinical Practice 2020, 39, https://doi.org/10.1016/j.ctcp.2020.101118.

23. Gross, J.J.; Jazaieri, H. Emotion, emotion regulation, and psychopathology: An affective science perspective. Clinical Psychological Science 2014, 2, 387-401, https://doi.org/10.1177/2167702614536164. 
24. Ozgundondu, B.; Metin, Z.G. Effects of progressive muscle relaxation combined with music on stress, fatigue, and coping styles among intensive care nurses. Intensive and Critical Care Nursing 2019, 54, 5463, https://doi.org/10.1016/j.iccn.2019.07.007.

25. Papadakakis, A.; Sidiropoulou, K.; Panagis, G. Music exposure attenuates anxiety-and depression-like behaviors and increases hippocampal spine density in male rats. Behavioural brain research 2019, 372, https://doi.org/10.1016/j.bbr.2019.112023.

26. Gregory, A.H. The roles of music in society: The ethnomusicological perspective. 1997.

27. Bonde, L.O.; Wigram, T. A comprehensive guide to music therapy: Theory, clinical practice, research and training. Jessica Kingsley Publishers: 2002.

28. Babikian, T.; Zeltzer, L.; Tachdjian, V.; Henry, L.; Javanfard, E.; Tucci, L.; Goodarzi, M.; Tachdjian, R. Music as medicine: a review and historical perspective. Alternative and Complementary Therapies 2013, 19, 251-254, https://doi.org/10.1089/act.2013.19510.

29. Habibi, A.; Damasio, A. Music, feelings, and the human brain. Psychomusicology: Music, Mind, and Brain 2014, 24, https://doi.org/10.1037/pmu0000033.

30. Fukui, H.; Toyoshima, K. Music facilitate the neurogenesis, regeneration and repair of neurons. Medical hypotheses 2008, 71, 765-769, https://doi.org/10.1016/j.mehy.2008.06.019.

31. Korsós, G.; Horváth, K.; Lukács, A.; Vezér, T.; Glávits, R.; Fodor, K.; Fekete, S.G. Effects of accelerated human music on learning and memory performance of rats. Applied animal behaviour science 2018, 202, 94-99, https://doi.org/10.1016/j.applanim.2018.01.011.

32. Xing, Y.; Chen, W.; Wang, Y.; Jing, W.; Gao, S.; Guo, D.; Xia, Y.; Yao, D. Music exposure improves spatial cognition by enhancing the BDNF level of dorsal hippocampal subregions in the developing rats. Brain research bulletin 2016, 121, 131-137, https://doi.org/10.1016/j.brainresbull.2016.01.009.

33. Yao, J.G.; Xia, Y.; Dai, S.J.; Fang, G.Z.; Guo, H.; Yao, D.Z. Enhancement of spatial learning-memory in developing rats via Mozart music. Journal of Electronic Science and Technology 2009, 7, 47-50.

34. Frith, E.; Loprinzi, P.D. Experimental effects of acute exercise and music listening on cognitive creativity. Physiology \& behavior 2018, 191, 21-28, https://doi.org/10.1016/j.physbeh.2018.03.034.

35. Kour, H.; Ravishankar, R.; Goudar, S. An experimental study to evaluate the effect of instrumental Indian classical and western music therapy on learning and memory in stress induced young rats. IOSR Journal of Pharmacy 2012, 2, 29-32.

36. Rauscher, F.; Robinson, D.; Jens, J. Improved maze learning through early music exposure in rats. Neurological research 1998, 20, 427-432, https://doi.org/10.1080/01616412.1998.11740543.

37. Jaušovec, N.; Jaušovec, K.; Gerlič, I. The influence of Mozart's music on brain activity in the process of learning. Clinical Neurophysiology 2006, 117, 2703-2714, https://doi.org/10.1016/j.clinph.2006.08.010.

38. Meng, B.; Zhu, S.; Li, S.; Zeng, Q.; Mei, B. Global view of the mechanisms of improved learning and memory capability in mice with music-exposure by microarray. Brain research bulletin 2009, 80, 36-44, https://doi.org/10.1016/j.brainresbull.2009.05.020.

39. Rajizadeh, M.A.; Esmaeilpour, K.; Masoumi-Ardakani, Y.; Bejeshk, M.A.; Shabani, M.; Nakhaee, N.; Ranjbar, M.P.; Borzadaran, F.M.; Sheibani, V. Voluntary exercise impact on cognitive impairments in sleepdeprived intact female rats. Physiology \& behavior 2018, 188, 58-66, https://doi.org/10.1016/j.physbeh.2017.12.030.

40. Esmaeilpour, K.; Sheibani, V.; Shabani, M.; Mirnajafi-Zadeh, J.; Akbarnejad, Z. Low Frequency Stimulation Reverses the Kindling-Induced Impairment of Learning and Memory in the Rat Passive-avoidance Test. Basic and clinical neuroscience 2018, 9, https://doi.org/10.29252/NIRP.BCN.9.1.51.

41. Kessler, R.C.; Sonnega, A.; Bromet, E.; Hughes, M.; Nelson, C.B. Posttraumatic stress disorder in the National Comorbidity Survey. Archives of general psychiatry 1995, 52, 1048-1060, https://doi.org/10.1001/archpsyc.1995.03950240066012.

42. Hendriksen, H.; Prins, J.; Olivier, B.; Oosting, R.S. Environmental enrichment induces behavioral recovery and enhanced hippocampal cell proliferation in an antidepressant-resistant animal model for PTSD. PLoS One 2010, 5, https://doi.org/10.1371/journal.pone.0011943.

43. Matar, M.A.; Cohen, H.; Kaplan, Z.; Zohar, J. The effect of early poststressor intervention with sertraline on behavioral responses in an animal model of post-traumatic stress disorder. Neuropsychopharmacology 2006, 31, https://doi.org/10.1038/sj.npp.1301132.

44. Zoladz, P.R.; D'Alessio, P.A.; Seeley, S.L.; Kasler, C.D.; Goodman, C.S.; Mucher, K.E.; Allison, A.S.; Smith, I.F.; Dodson, J.L.; Stoops, T.S. A predator-based psychosocial stress animal model of PTSD in females: Influence of estrous phase and ovarian hormones. Hormones and behavior 2019, 115, https://doi.org/10.1016/j.yhbeh.2019.104564.

45. Shang, C.; Guo, Y.; Yao, J.Q.; Fang, X.X.; Sun, L.J.; Jiang, X.Y.; Ding, Z.C.; Ran, Y.H.; Wang, H.L; Zhang, L.M. Rapid anti-PTSD-like activity of the TSPO agonist YL-IPA08: Emphasis on brain GABA, neurosteroids and HPA axis function. Behavioural brain research 2020, 379, https://doi.org/10.1016/j.bbr.2019.112320.

46. Stawski, R.S.; Sliwinski, M.J.; Smyth, J.M. Stress-related cognitive interference predicts cognitive function in old age. Psychology and aging 2006, 21, https://doi.org/10.1037/0882-7974.21.3.535. 
47. Sbarski, B.; Akirav, I. Cannabinoids as therapeutics for PTSD. Pharmacology \& Therapeutics 2020, 211, https://doi.org/10.1016/j.pharmthera.2020.107551.

48. Masoumi-Ardakani, Y.; Mahmoudvand, H.; Mirzaei, A.; Esmaeilpour, K.; Ghazvini, H.; Khalifeh, S.; Sepehri, G. The effect of Elettaria cardamomum extract on anxiety-like behavior in a rat model of posttraumatic stress disorder. Biomedicine \& Pharmacotherapy 2017, 87, 489-495, https://doi.org/10.1016/j.biopha.2016.12.116.

49. Kohda, K.; Harada, K.; Kato, K.; Hoshino, A.; Motohashi, J.; Yamaji, T.; Morinobu, S.; Matsuoka, N.; Kato, $\mathrm{N}$. Glucocorticoid receptor activation is involved in producing abnormal phenotypes of single-prolonged stress rats: a putative post-traumatic stress disorder model. Neuroscience 2007, 148, 22-33, https://doi.org/10.1016/j.neuroscience.2007.05.041.

50. Harvey, B.H.; Naciti, C.; Brand, L.; Stein, D.J. Endocrine, cognitive and hippocampal/cortical 5HT1A/2A receptor changes evoked by a time-dependent sensitisation (TDS) stress model in rats. Brain research 2003, 983, 97-107, https://doi.org/10.1016/S0006-8993(03)03033-6.

51. Wang, H.T.; Han, F.; Gao, J.L.; Shi, Y.X. Increased phosphorylation of extracellular signal-regulated kinase in the medial prefrontal cortex of the single-prolonged stress rats. Cellular and molecular neurobiology 2010, 30, 437-444, https://doi.org/10.1007/s10571-009-9468-1.

52. Elizalde, N.; Gil-Bea, F.J.; Ramirez, M.J.; Aisa, B.; Lasheras, B.; Del Rio, J.; Tordera, R.M. Long-lasting behavioral effects and recognition memory deficit induced by chronic mild stress in mice: effect of antidepressant treatment. Psychopharmacology 2008, 199, https://doi.org/10.1007/s00213-007-1035-1.

53. Chida, Y.; Sudo, N.; Mori, J.; Kubo, C. Social isolation stress impairs passive avoidance learning in senescence-accelerated mouse (SAM). Brain research 2006, 1067, 201-208, https://doi.org/10.1016/j.brainres.2005.10.042.

54. Brewin, C.R.; Kleiner, J.S.; Vasterling, J.J.; Field, A.P. Memory for emotionally neutral information in posttraumatic stress disorder: A meta-analytic investigation. Journal of abnormal psychology 2007, 116, 448, https://doi.org/10.1037/0021-843X.116.3.448.

55. Buchanan, T.W.; Kern, S.; Allen, J.S.; Tranel, D.; Kirschbaum, C. Circadian regulation of cortisol after hippocampal damage in humans. Biological Psychiatry 2004, 56, 651-656, https://doi.org/10.1016/j.biopsych.2004.08.014.

56. Lucassen, P.; Meerlo, P.; Naylor, A.; Van Dam, A.; Dayer, A.; Fuchs, E.; Oomen, C.; Czeh, B. Regulation of adult neurogenesis by stress, sleep disruption, exercise and inflammation: Implications for depression and antidepressant action. European Neuropsychopharmacology 2010, 20, 1-17, https://doi.org/10.1016/j.euroneuro.2009.08.003.

57. Alexander, W. Pharmacotherapy for post-traumatic stress disorder in combat veterans: focus on antidepressants and atypical antipsychotic agents. Pharmacy and Therapeutics 2012, 37, 32.

58. Holtzheimer III, P.E.; Nemeroff, C.B. Future prospects in depression research. Dialogues in clinical neuroscience 2006, 8, 175-179.

59. Escribano, B.; Quero, I.; Feijóo, M.; Tasset, I.; Montilla, P.; Túnez, I. Role of noise and music as anxiety modulators: Relationship with ovarian hormones in the rat. Applied Animal Behaviour Science 2014, 152, 73-82, https://doi.org/10.1016/j.applanim.2013.12.006.

60. Hartwig, R. Music therapy in the context of palliative care in Tanzania. International journal of palliative nursing 2010, 16, 499-504, https://doi.org/10.12968/ijpn.2010.16.10.79215.

61. Meng, B.; Zhu, S.; Li, S.; Zeng, Q.; Mei, B. Global view of the mechanisms of improved learning and memory capability in mice with music-exposure by microarray. Brain research bulletin 2009, 80, 36-44, https://doi.org/10.1016/j.brainresbull.2009.05.020.

62. Amagdei, A.; Balteş, F.R.; Avram, J.; Miu, A.C. Perinatal exposure to music protects spatial memory against callosal lesions. International Journal of Developmental Neuroscience 2010, 28, 105-109, https://doi.org/10.1016/j.ijdevneu.2009.08.017.

63. Zheng, M.Q.; Yin, D.Z.; Zhang, L.; Lei, B.; Cheng, D.F.; CAI, H.C.; Han, Y.J.; WU, M.X.; Zhang, H.; Wang, J. Biological characters of [18F] O-FEt-PIB in a rat model of Alzheimer's disease using micro-PET imaging 1. Acta Pharmacologica Sinica 2008, 29, 548-554, https://doi.org/10.1111/j.17457254.2008.00785.x. 